\title{
Pelatihan Penulisan Karya Ilmiah Bagi Guru-Guru Sekolah Dasar Untuk Meningkatkan Kompetensi Profesionalisme Guru
}

\author{
Sri Lestari Handayani ${ }^{1}$, Trie Utari Dewi ${ }^{2}$ \\ ${ }^{1}$ Prodi Pendidikan Guru Sekolah Dasar FKIP UHAMKA \\ ${ }^{2}$ Prodi Pendidikan Bahasa dan Sastra Indonesia FKIP UHAMKA \\ Email: srilestarih@uhamka.ac.id ${ }^{1}$, trie.utari.dewi@uhamka.ac.id ${ }^{2}$
}

\begin{abstract}
ABSTRAK
Kegiatan pengabdian ini dilatarbelakangi permasalahan mitra yang diidentifikasi meliputi 1) Umumnya para guru merasa enggan untuk mengurus kenaikan pangkat/golongan karena persyaratan yang dirasa berat; 2) Kebanyakan guru stagnan pada pangkat/golongan IVa; 3) Guru kurang paham cara membuat karya ilmiah yang sesuai dengan standar; dan 4) Guru tidak tahu bagaimana cara mempublikasikan karya ilmiah. Adapun solusi yang ditawarkan ialah memberikan pelatihan penulisan karya tulis ilmiah bagi guru-guru SDN Kebon Pala 11, 12, dan 13 Pagi Jakarta Timur. Target luaran pengabdian ini berupa jasa pelatihan berupa informasi bagi guru-guru SDN Kebon Pala 11, 12, dan 13 Pagi terkait penulisan karya tulis ilmiah dan publikasi artikel ilmiah. Melalui kegiatan pengabdian yang telah dilakukan memiliki tiga hal yang ditingkatkan yaitu (1) memperdalam pengetahuan guru tentang karya tulis ilmiah, (2) mengenalkan dan menggalakkan kegiatan menulis artikel ilmiah di jurnal untuk meningkatkan kompetensi profesionalisme guru dan (3) memotivasi guru-guru untuk mulai mempublikasikan karya tulis ilmiah berupa artikel ilmiah di jurnal. Metode yang digunakan adalah metode ceramah, diskusi, dan tanya jawab. Hasil dari pelaksanaan kegiatan pengabdian masyarakat ini yaitu memberikan pemahaman tentang karya tulis ilmiah, alasan mengapa guru harus membuat karya ilmiah, konsep karya tulis ilmiah, dan proses menulis karya ilmiah. Selanjutnya para guru mendapatkan materi tentang cara mempublikasikan karya tulis ilmiah beserta tahapan-tahapannya. Lalu peserta diminta untuk membuat karya ilmiah sebagai tindak lanjut untuk kegiatan pengabdian berikutnya.
\end{abstract}

Kata Kunci: guru sekolah dasar; penulisan karya ilmiah; profesionalisme guru.

\section{ABSTRACK}

This devotion activity is motivated by partner problems identified including 1) Generally the teachers feel reluctant to take care of promotion / class because the requirements are considered heavy; 2) Most teachers are stagnant in rank IVa; 3) The teacher does not understand how to make scientific work in accordance with the standards; and 4) The teacher does not know how to publish scientific work. The solution offered is to provide training in writing scientific papers for teachers at SDN Kebon Pala 11, 12 and 13 in East Jakarta. The target of this devotion output is training services in the form of information for teachers of Kebon Pala Elementary School 11, 12 and 13 in the morning related to scientific writing and publication of scientific articles. Through the devotion activities that have been carried out, three things have been improved, that is (1) deepening the teacher's knowledge of scientific papers, (2) introducing and promoting the activities of writing scientific articles in journals to improve teacher professional competence and (3) motivating teachers to start publish scientific papers in the form of scientific articles in journals. The method used is the method of lecture, discussion, and question and answer. The results of the implementation of community devotion activities are to provide an understanding of scientific writing, the reason why the teacher must make scientific work, the concept of scientific writing, and the process of writing scientific papers. Next the teachers get material about how to publish scientific papers along with the stages. Then participants are asked to make scientific work as a follow-up to their next devotion activities.

Keywords: primary school teachers; teacher professionalism; writing scientific work. 


\section{PENDAHULUAN}

Guru adalah pendidik profesional dengan tugas utama mendidik, mengajar, membimbing, mengarahkan, melatih, menilai, dan mengevaluasi peserta didik pada pendidikan anak usia dini jalur pendidikan formal, pendidikan dasar, dan pendidikan menengah. Dalam melaksanakan tugas keprofesionalan, guru berkewajiban merencanakan pembelajaran, melaksanakan proses pembelajaran yang bermutu, serta menilai dan mengevaluasi hasil pembelajaran. Disamping hal tersebut guru juga wajib meningkatkan dan mengembangkan kualifikasi akademik dan kompetensi secara berkelanjutan sejalan dengan perkembangan ilmu pengetahuan, teknologi dan seni (Setiwan dan Tri Mulyani, 2014: 3). Salah satu cara untuk memenuhi kualifikasi akademik dan kompetensi IPTEK secara berkelanjutan adalah dengan mengurus jabatan fungsional guru sebagaimana Keputusan Menteri Negara Pendayagunaan Aparatur Negara dan Reformasi Birokrasi No. 16 Tahun 2009 tentang Jabatan Fungsional Guru dan Angka Kreditnya yang salah satu isinya menjabarkan tentang pengembangan keprofesian berkelanjutan meliputi pengembangan diri, publikasi ilmiah, dan karya inovatif. Di mana untuk kenaikan jabatan/pangkat setingkat lebih tinggi dari Guru Pertama, pangkat Penata Muda, golongan ruang III/a sampai dengan Guru Utama, pangkat Pembina Utama, golongan ruang IV/e wajib melakukan kegiatan pengembangan keprofesian berkelanjutan yang meliputi sub unsur pengembangan diri, publikasi ilmiah, dan/atau karya inovatif.

Berdasarkan keputusan tersebut, maka guru diwajibkan untuk membuat karya tulis ilmiah yang dipublikasikan agar dapat naik ke jenjang pangkat berikutnya. Namun sayangnya, untuk guru-guru Sekolah Dasar pada umumnya menulis karya ilmiah masihlah sebuah momok. Para guru merasa kurang mampu dalam membuat Karya Tulis Ilmiah sehingga mereka enggan, bahkan apatis untuk mengurus kepangkatannya atau kenaikan golongannya. Adapun guru yang telah mencoba untuk melengkapi persyaratan kepangkatannya, banyak yang belum lulus karena karya tulis ilmiah yang dibuatnya masih banyak yang harus direvisi dan belum memenuhi standar yang diharapkan. Sebagai guru yang berkecimpung di dunia pendidikan, sudah seharusnya untuk terus menerus menambah dan mengembangkan wawasan serta pemahamannya baik yang berkaitan secara langsung dengan mata pelajarannya yang diampunya maupun secara tidak langsung. Untuk itulah guru harus mampu membuat karya tulis ilmiah dan menjadikannya sebagai suatu kebutuhan.

Berdasarkan permasalahan tersebut, maka perlu dilakukan kegiatan pelatihan Penulisan Karya Ilmiah bagi guru-guru di SDN Kebon Pala 12 Pagi yang memiliki permasalahan yang sama. Mitra yang 
menjadi peserta kegiatan adalah guruguru SDN Kebon Pala 11, 12, dan 13

Pagi Jakarta Timur. Pelaksanaan kegiatan pengabdian ini diselenggarakan di SDN Kebon Pala 12, Jakarta Timur.

Guru-guru di sekolah dasar tersebut dalam menjalankan tugas utama mendidik, mengajar, dan membimbing sudah sangat baik. Dalam kegiatan pembelajaran di kelaspun sudah cukup baik. Namun sayangnya banyak guru-guru yang tidak melakukan pengembangan keprofesian berkelanjutan untuk meningkatkan profesionalitasnya. Sebagaimana yang telah diungkapkan di atas, bahwa salah satu syarat untuk kenaikan golongan adalah publikasi ilmiah. Dengan kata lain, guru diharuskan membuat karya tulis ilmiah. Di mana guru-guru SDN Kebon Pala 11, 12, dan 13 Pagi Jakarta Timur masih merasa kesulitan dalam membuat karya tulis ilmiah serta tidak tahu bagaimana cara untuk dapat mempublikasikan karya ilmiah tersebut. Untuk itulah bentuk pelatihan penulisan karya ilmiah yang dilaksanakan menjadi salah satu solusi tepat untuk diberikan kepada para guru agar dapat lulus dalam pengajuan peryaratan kenaikan golongan.

Dipilihnya pelatihan penulisan karya ilmiah yaitu berdasarkan pertimbangan:

1. Permintaan khusus dari mitra.

2. Untuk memotivasi para guru dalam mengurus kenaikan pangkat/golongan.
3. Untuk menambah dan mengembangkan wawasan serta profesionalitasnya sebagai guru.

Pengusul dan mitra bersepakat memilih kegiatan pelatihan penulisan karya ilmiah agar para guru tidak lagi kesulitan dalam membuat karya tulis ilmiah sehingga dapat lulus dalam pengajuan kenaikan kepangkatan/ golongan, sehingga para guru dapat memenuhi profesionalitasnya sebagai guru. Selain itu, dapat menambah dan mengembangkan wawasan para guru baik secara langsung dengan mata pelajaran yang diampunya, maupun secara tidak langsung.

\section{METODE PENELITIAN}

Kegiatan pengabdian ini berupa pelatihan penulisan karya ilmiah kepada guru-guru SDN Kebon Pala 11, 12, dan 13 Pagi Jakarta Timur. Kegiatan dilakukan selama enam bulan dengan jumlah peserta sebanyak 20 orang guru. Pelaksanaan kegiatan dilakukan di SDN Kebon Pala 12 Pagi Jakarta Timur.

Bentuk kegiatan dalam pengabdian ini yaitu dengan memberikan materi pelatihan yang meliputi:

1. Materi 1: pemahaman tentang karya ilmiah, alasan mengapa guru harus membuat karya ilmiah, konsep karya tulis ilmiah, dan proses menulis karya ilmiah.

2. Materi 2: pemahaman tentang cara mempublikasi karya ilmiah, format penulisan sampai dengan pengiriman karya ilmiah untuk dipublikasi. 
Selanjutnya, memberikan pengarahan dalam membuat karya tulis ilmiah serta rencana tindak lanjutnya.

Metode pelatihan kegiatan pengabdian yang digunakan yaitu:

1. Metode Ceramah, dipilih untuk memberikan pemahaman dan penjelasan tentang cara membuat karya tulis ilmiah serta cara mempublikasikannya.

2. Metode Tanya Jawab, dipilih agar para guru dapat memperdalam materi pelatihan yang diberikan dengan cara mengajukan pertanyaan.

Adapun langkah-langkah kegiatan yang dilakukan adalah sebagai berikut.

1. Tahap Persiapan

Tahap persiapan yang dilakukan meliputi: 1) survey, 2) pemantapan dan penentuan lokasi sasaran, 3) komunikasi dengan mitra melalui kepala SDN Kebon Pala 12 Pagi dan mengurus surat kerjasama mitra.

2. Tahap Pelaksanaan

Pelaksanaan dilaksanakan selama satu kali. Rincian kegiatan yang dilakukan adalah memberikan pemahaman tentang karya tulis ilmiah, alasan mengapa guru harus membuat karya ilmiah, konsep karya tulis ilmiah, dan proses menulis karya ilmiah. Selanjutnya para guru diberikan materi tentang cara mempublikasikan karya tulis ilmiah beserta tahapantahapannya. Lalu peserta diminta untuk membuat karya ilmiah.
3. Tahap Evaluasi

Tahap evaluasi kegiatan ini adalah melakukan pembicaraan dengan guru-guru peserta kegiatan dengan membentuk tiga kelompok yang akan melakukan penelitian tindakan kelas dan membuat artikel dari PTK yang dilakukan kemudian melakukan submit artikel tersebut ke jurnal. Hasil evaluasi akan digunakan untuk melakukan kegiatan pengabdian lanjutan.

\section{HASIL DAN PEMBAHASAN}

Kegiatan pengabdian "PKM Pelatihan Penulisan Karya Ilmiah Bagi Guru-Guru SDN Kebon Pala 12 Pagi Jakarta Timur" telah dilaksanakan pada tanggal 8 Februari 2019. Kegiatan ini dilaksanakan di SDN Kebon Pala 12 Pagi dimulai dari $13.00-16.00$ WIB. Kegiatan pengabdian yang telah dilaksanakan menitikberatkan pada pemahaman guru-guru SD tentang publikasi di jurnal dan memotivasi guru untuk membuat karya tulis ilmiah.

Narasumber

kegiatan pengabdian ini adalah Trie Utari Dewi, S.S., M.Hum dan Sri Lestari Handayani, M.Pd. Pada bagian pertama, materi diberikan oleh Trie Utari Dewi, S.S., M.Hum berupa pengenalan karya tulis ilmiah dan pentingnya publikasi bagi guru-guru SD. Paparan materi diberikan selama 45 menit dan 15 menit untuk tanya jawab.

Poin-poin penting materi yang dijelaskan meliputi: karakteristik 
karya tulis ilmiah, karakteristik karya tulis non ilmiah, jenis-jenis karya tulis ilmiah, pentingnya membuat karya tulis ilmiah, kesulitan dalam menulis karya tulis ilmiah, tips dan trik unuk menulis karya tulis ilmiah, pentingnya membaca literatur untuk mempermudah menulis karya tulis ilmiah, tahapan dalam menulis karya ilmiah, cara menulis laporan hasil penelitian, dan contoh-contoh PTK yang pernah dilakukan oleh guru.

Setelah selesai paparan materi kemudian dilanjutkan dengan sesi tanya jawab. Beberapa pertanyaan yang muncul terkait karya tulis ilmiah di antaranya adalah: (1) apakah skripsi termasuk jenis karya tulis ilmiah?; (2) bagaimana membuat karya tulis ilmiah yang baik dan benar mengingat ketika dihadapkan kepada dosen pembimbing selalu salah?; (3) bagaimana membuat penelitian tindakan kelas yang benar?; (4) apakah sistematika PTK sama dengan sistematika skripsi?; (5) jika seorang guru melakukan PTK, siapa yang bertindak sebagai dosen pembimbing?; dan (6) apakah PTK dapat dilakukan oleh beberapa guru atau kolaborasi begitu?".

Dari beberapa pertanyaan yang dikemukakan oleh peserta kegiatan pengabdian diperoleh gambaran bahwa guru ragu untuk melakukan PTK dikarenakan beberapa hal yaitu kekurangan pengetahuan yang cukup untuk melakukan PTK, kurangnya kepercayaan diri peserta kegiatan pengabdian ini dalam melaksanakan PTK, konsep tentang karya tulis ilmiah yang baik dan benar belum dipahami dengan baik, dan konsep tentang pelaksanaan suatu penelitian seperti PTK yang bisa dilakukan berkolaborasi mengingat kekurangpahaman guru terkait PTK.

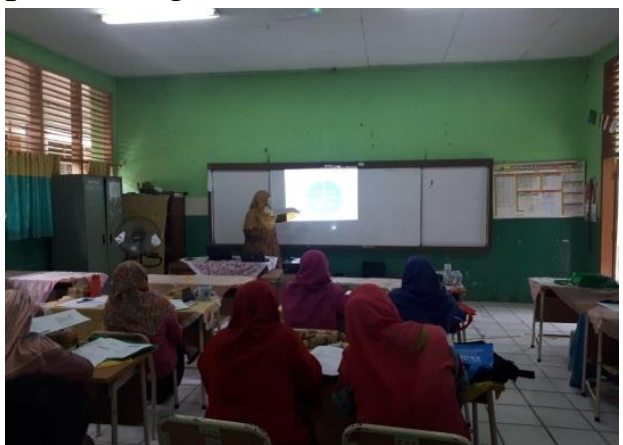

Gambar 1. Penyampaian Materi Pertama

Pada sesi kedua, paparan materi diberikan oleh Sri Lestari Handayani, M.Pd. Paparan materi diberikan waktu selama 45 menit. Materi yang diberikan dibagi menjadi dua poin utama yaitu (1) Penulisan artikel ilmiah, dan (2) Publikasi di Jurnal. Poin pertama terkait penulisan artikel ilmiah, beberapa hal yang dijelaskan meliputi perbedaan format artikel ilmiah hasil penelitian dan artikel ilmiah bukan hasil penelitian, unsur penting artikel ilmiah, penjelasan lengkap terkait judul, abstrak dan tipe abstrak, kata kunci, pendahuluan, metode, hasil dan pembahasan, simpulan, saran, dan ucapan terimakasih. Poin utama kedua terkait publikasi di jurnal berisi tentang proses bagiaimana suatu artikel diproses mulai submit hingga publish dan cara registrasi untuk memperoleh akun di suatu jurnal. Pada kegiatan ini, jurnal yang dijadikan contoh adalah Jurnal Inovasi Pendidikan Dasar (JIPD) 
yang dikelola oleh PGSD UHAMKA dan pemateri sebagai salah satu editor di jurnal tersebut.Hari kedua dilaksanakan permainan lanjutan bagi siswa.

Selesainya paparan materi kemudian dilanjutkan dengan sesi tanya jawab oleh peserta kegiatan pengabdian. Beberapa pertanyaan yang diberikan peserta kepada pemateri diantaranya adalah (1) Apa fungsi dari kata kunci dan bagaimana memilih kata kunci yang benar?; (2) jurnal itu apa dan bagaimana memilih jurnal yang cocok dengan artikel yang dibuat?; (3) bagaimana menulis artikel dari hasil PTK?; dan (4) apakah artikel yang dibuat boleh dipublish selain di jurnal?". Beberapa pertanyaan yang diajukan oleh peserta memberikan gambaran kepada tim pengabdian bahwa mayoritas guru belum pernah melakukan atau membuat artikel ilmiah. Hal ini dikarenakan guru tidak memiliki bahan yang cukup dan pengetahuan yang cukup untuk membuat artikel ilmiah. Kurangnya pengalaman membuat PTK membuat guru tidak memiliki materi untuk publikasi. Sebagian besar guru tampak awam atau tidak biasa mendengar istilah jurnal. Tim pengabdian juga menemukan bahwa belum ada satu pun peserta kegiatan yang pernah mempublish artikel ilmiah di jurnal. Enam dari 20 peserta yang merupakan guru berstatus PNS (pegawai negeri sipil) tidak pernah membuat dan mempublikasikan satu artikel pun. Hal ini dikarenakan pengetahuan dan pengalaman membuat artikel ilmiah belum memadai. Kegiatan pengabdian yang dilaksanakan memberikan pengetahuan kepada peserta terkait artikel ilmiah.

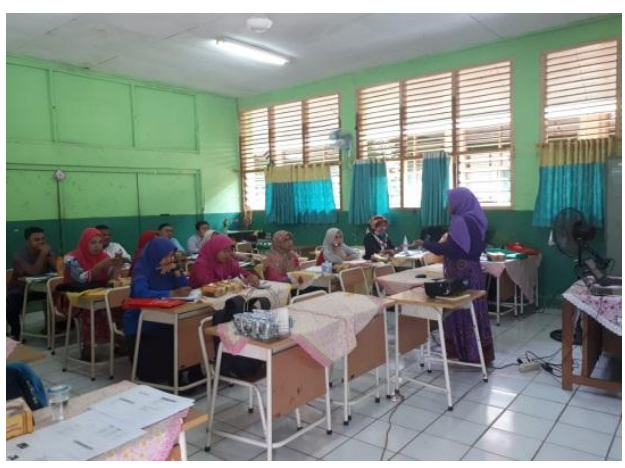

Gambar 2. Penyampaian Materi Kedua

Publikasi ilmiah, salah satunya publikasi di jurnal merupakan salah satu bagian dari peningkatan profesionalisme guru khususnya guru yang berstatus PNS di mana ketika mengajukan kenaikan pangkat maka publikasi menjadi salah satu poin penilaian. Temuan kegiatan pengabdian ini menunjukkan bahwa guru-guru di SDN Kebon Pala 11, 12, dan 13 Pagi masih lemah dalam publikasi ilmiah. Lemahnya publikasi ilmiah yang dialami guru menjadi salah satu kendala ketika guru mengajukan kenaikan pangkat. Lemahnya publikasi ilmiah dikarekan pengetahuan dan pengalaman yang belum memadai khususnya publikasi di jurnal.

Guru memiliki kesempatan yang besar untuk meningkatkan profesionalismenya melalui publikasi karena guru memiliki kesempatan yang luas untuk melakukan penelitian tindakan kelas setiap saat. Hasil PTK yang diperoleh menjadi bahan untuk 
membuat artikel ilmiah dan kemudian disubmit ke jurnal yang sesuai. Dua manfaat besar ketika guru melakukan PTK yaitu menyelesaikan masalah di kelas melalui PTK dan menggunakan hasil PTK tersebut untuk dibuat dalam bentuk artikel dan dipublikasikan (Afandi, 2014). Jika dapat dilakukan oleh guru-guru peserta kegiatan pengabdian ini maka guru dapat meningkatkan profesionalismenya. Hal ini sesuai dengan hasil pengabdian (Aina, H, SB, H, \& Sadikin, 2015; Aisyah \& Mahanani, 2017; Zm, Muntari, \& Jufri, 2018) yang menyatakan bahwa pelatihan penulisan karya tulis dapat meningkatkan kemampuan profesionalisme guru. Salah satu upaya meningkatkan kemampuan menulis artikel ilmiah guru dapat melalui kegiatan pengabdian masyarakat (Marwoto, Sopyan, Linuwih, \& Subali, 2013).

Temuan kegiatan pengabdian ini memberikan informasi bahwa guru-guru di SDN Kebon Pala 11, 12, dan 13 Pagi memerlukan tindak lanjut berupa pendampingan PTK dan pendampingan menulis artikel ilmiah. Hasil kegiatan pengabdian ini diperoleh tiga kelompok guru yang akan melakukan PTK yaitu kelompok SDN Kebon Pala 11 Pagi yang diketuai oleh Ibu Melina, S.Pd, kelompok SDN Kebon Pala 12 Pagi yang diketuai oleh Ibu Umi, S.Pd, dan Kelompok SDN Kebon Pala 13 Pagi yang diketuai oleh Ibu Yuli, S.Pd. Kegiatan selanjutnya direncanakan berupa tindakan lanjut dari hasil kegiatan pengabdian ini. $\begin{array}{lr}\text { Kegiatan } & \text { pengabdian } \\ \text { dilanjutkan dengan pemberikan } \\ \text { plakat kepada perwakilan salah satu }\end{array}$ peserta. Kegiatan dilanjutkan dengan pemberian kesan pesan oleh salah satu peserta yang diwakili oleh Bapak Rusli, S.Pd. Peserta termotivasi untuk dapat melakukan PTK dan memiliki keinginan besar untuk bisa memiliki artikel yang dipublish di jurnal ilmiah. Kesan dan pesan yang disampaikan oleh salah satu peserta mewakili keinginan semua peserta di mana hampir semua peserta menghendaki adanya tindak lanjut berupa praktek langsung dalam pembuatan artikel ilmiah. Untuk itu, kegiatan pengabdian selanjutnya berupa pendampingan PTK dan pendampingan pembuatan artikel ilmiah. Ketika guru mempraktekkan pengetahuan tentang artikel ilmiah diharapkan guru mampu memahami cara menulis artikel ilmiah dengan lebih baik. Kegiatan pengabdian diakhiri dengan sesi foto bersama.

\section{SIMPULAN}

Kegiatan pengabdian yang telah dilaksanakan menghasilkan beberapa simpulan yaitu:

1. kegiatan "PKM Pelatihan Penulisan Karya Ilmiah Bagi Guru-Guru SDN Kebon Pala 11, 12, dan 13 Pagi Jakarta Timur" memberikan pengetahuan baru bagi guru-guru di sekolah tersebut terkait alternatif mempublikasikan karya tulis ilmiah berbentuk artikel ilmiah di jurnal. 
2. materi-materi yang disampaikan oleh narasumber dalam kegiatan pengabdian memberikan jawaban dan solusi atas permasalah para guru dalam membuat karya ilmiah. Selain itu juga, kegiatan pengabdian ini memberi motivasi tersendiri bagi para guru untuk membuat penelitian tindakan kelas yang dapat dipublikasikan dalam jurnal.

\section{DAFTAR PUSTAKA}

Afandi, M. (2014). Pentingnya Penelitian Tindakan Kelas Bagi Guru dalam Pembelajaran di Sekolah Dasar. Jurnal Ilmiah Pendidikan Dasar, 1(1), 1-19.

Aina, M., H, B., SB, R., H, A., \& Sadikin, A. (2015). Pelatihan Penulisan Karya Tulis Ilmiah Bagi Guru-Guru SMA 8 Kota Jambi. Jurnal Pengabdian Pada Masyarakat, 30(3), 29-32.

Aisyah, E. N., \& Mahanani, P. (2017). Pelatihan Menulis Artikel Ilmiah Bagi Guru Sekolah Dasar dan Taman Kanak-Kanak Kecamatan Tajinan Kabupaten Malang. ABDIMAS PEDAGOGI, 1(1), 22-26.

Marwoto, P., Sopyan, A., Linuwih, S., \& Subali, B. (2013). Peningkatan Kemampuan Menulis Artikel Ilmiah Sains Guru Sekolah Dasar Melalui Kegiatan Pengabdian Masyarakat. ABDIMAS, 17(2), 111-116.

Setiawan, Wawan dan Tri Mulyadi. 2014. Pelatihan Penulisan
Karya Ilmiah Bagi Guru Sekolah Menengah Pertama dan Sekolah Menengah Atas/Sederajad di Kecamatan Mijen Kota Semarang. Semarang: Artikel Pengabdian Universitas Semarang

SK Menteri Negara Pendayagunaan Aparatur Negara dan Reformasi Birokrasi No. 16 Tentang Jabatan Fungional Guru dan Angka Kreditnya.

Zm, H., Muntari, \& Jufri, A. W. (2018). Jurnal Pengabdian Magister Pendidikan IPA Pelatihan Penulisan dan Penyuntingan Karya Ilmiah bagi Guru-Guru MTS dan MA Pondok Pesantren Azziziyah Kapek di Kecamatan Gunungsari Kabupaten Lombok Barat. Jurnal Pengabdian Magister Pendidikan IPA, 1(1), 75-78. 